\title{
Sistem Kontrol Suhu dan Waktu Otomatis Mesin Roasting Kopi Portabel
}

\author{
Rahman Arifuddin ${ }^{1}$, Irfan Mujahidin $^{2}$, Subairi $^{3}$ dan Respati Wikantiyoso ${ }^{4}$ \\ 1,2,3,4 Universitas Merdeka Malang \\ Jalan Terusan Dieng No.62-64, Malang 65146 \\ e-mail: rahman.arifuddin@unmer.ac.id
}

\begin{abstract}
Abstrak - Proses roasting kopi secara manual dengan mengabaikan suhu dan waktu sangria dapat menimbulkan masalah yaitu pada tingkat kematangan dan aroma kopi tersebut. Permasalahan ini perlu diberikan solusi untuk proses sangria pada penentuan suhu dan waktu sangria. System kendali otomatis dalam penerapannya pada suhu dan waktu sangria dapat dilakukan dengan merancang system kendali otomatis pada suhu dan waktu sangria . Metode fuzzy logic dapat diterapkan pada system kendali tersebut dengan input suhu dan jumlah kopi yang akan disangrai serta output berupa waktu proses sangria. Dimana jumlah kopi dengan suhu yang telah ditentukan akan memberikan pengaruh pada waktu proses sangrai, jumlah kopi 100 gram dengan suhu $110^{\circ} \mathrm{C}$ membutuhkan waktu sangrai $\pm \mathbf{5 0}$ menit.
\end{abstract}

Kata kunci: Roasting, Fuzzy Logic, Sistem Kendali

\begin{abstract}
The manual roasting process regardless of the temperature and roasting time can cause problems, namely the level of ripeness and aroma of the coffee. This problem needs a solution for the roasting process in determining the temperature and roasting time. Automatic control system in its application to roast temperature and time can be done by designing an automatic control system on the temperature and time of the roast. The fuzzy logic method can be applied to the control system by inputting the temperature and the amount of coffee to be roasted and the output in the form of the sangria processing time. Where the amount of coffee with a predetermined temperature will have an influence on the roasting process, the amount of coffee 100 grams with a temperature of $1100 \mathrm{C}$ requires roasting time +50 minutes
\end{abstract}

Keywords: Roasting, Fuzzy logic, Control System

\section{PENDAhULUAN}

Kopi dapat dikategorikan sebagai komoditas perkebunan yang memiliki pangsa pasar mulai dari kalangan ekonomi bawah sampai atas. Kopi merupakan salah satu komoditas strategis yang masuk dalm program pemerintah untuk dikembangkan yang memiliki target ekspor tiga kali lipat selama tahun 2020-2024 [1], selain enam komoditas lainnya seperti kakao, kelapa, lada, pala vanili dan jambu mete. Kopi juga diharapkan mampu meningkatkan devisa ekspor Indonesia [2]

Kabupaten Malang terletak diwilayah dataran tinggi antara 0-2000 m dpl merupakan salah satu penghasil kopi robusta memiliki kualitas dan rasa yang diakui oleh dunia. Kecamatan Dampit memiliki kopi Dampit dengan jenis robusta yang hampir $90 \%$ diekspor keluar negeri [3]. Kementerian Pertanian melalui Badan Karantina Pertanian menyebutkan bahwa telah melepas ekspor kopi robusta asal malang ke tiga negara sekaligus, yaitu Mesir, Italia dan Jepang.

Minuman kopi dapat dibedakan atas tingkat keasaman dan rasanya setelah melewati proses pengolahan. Faktor yang memperngaruhi hal tersebut adalah faktor alam dimana kopi tersebut ditanam, misalkan tinggi permukaan tanah, jenis tanah dan proses budidayanya. Untuk rasa dan aroma pada kopi dapat terbentuk setelah proses pasca panen, yaitu proses Roasting[4][5]. Tingkat kematangan pada saat proses Roasting dapat menciptakan rasa dan aroma yang berbeda.
Permasalahan pada saat proses Roasting yang masih manual adalah penentuan suhu dan lama proses Roasting dalam satu kali produksi. Solusi untuk permasalah tersebut adalah dengan merancang system kendali dan otomasi pada mesin roasting kopi. Dengan mengontrol dan mengendalikan suhu dengan menggunakan metode fuzzy logic pada proses Roasting diharapkan dapat menciptakan rasa dan aroma yang berbeda serta proses produksi lebih cepat.

\section{STUDI PUSTAKA}

\section{A. Proses Roasting Kopi}

Proses Roasting dilakukan dengan melakukan kombinasi dari perlakuan suhu dan waktu Roasting. Pengaruh dari suhu dan waktu Roasting biji kopi adalah pada kadar air kopi tersebut. Selain kadar air, kadar abu juga dapat meningkat sesuai dengan suhu dan waktu Roasting. Semakin tinggi suhu dan semakin lama proses Roasting kadar abu biji kopi semakin besar

\section{B. Sensor K-Type Thermocouple}

K TYPE THERMOCOUPLE SENSOR MAX6675 merupakan module sensor suhu yang memiliki kemampuan pengukuran suhu sangat tinggi, dimana probenya mampu 
mengukur suhu dengann rentang 0C - 400C [6][7][8]. Sensor ini menggunakan IC MAX6675 yang dapat dengan mudah dikoneksikan pada Arduino atau minsys lainnya dengan menggunakann komunikasi SPI[9]

\section{MetODE}

Pada system control mesin roasting kopi dengan menggunakan metode fuzzy logic mamdani. beberapa tahapan dilakukan pengujian pada setiap blok diagram mulai dari pengujian input dan output.

Berdasarkan gambar.. sensor suhu memiliki peran untuk mendeteksi suhu pada ruang roasting kopi. Keypad berfungsi untuk mensetting berapa lama waktu dan suhu yang diperlukan, karena didalam system akan ada tiga menu yang akan tampil pada LCD. Elemen panas berfungsi sebagai sumber panas untuk kondisi roasting, dperlukan juga blower untuk menurunkan panas jika kondisi suhu dalam ruang roasting melebihi suhu yang telah ditenetukan.

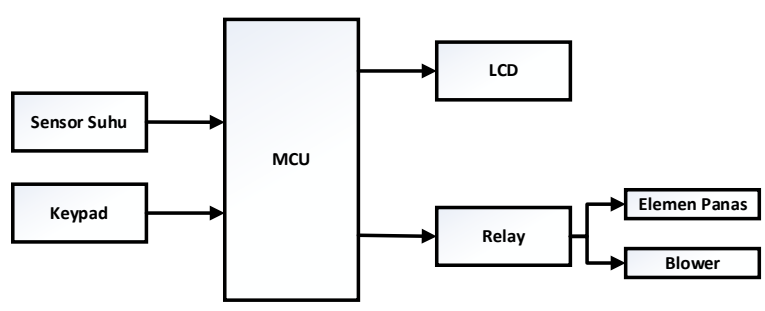

Gambar 1. Blok Diagram Sistem

Untuk system control menggunakan fuzzy logic mamdani yang biasa disebut dengan metode min-max, dimana system ini sangat cocok untuk penggunaan sensor suhu, dimana perubahan yang dideteksi oleh sensor suhu tidak menentu. Variable input yaitu jumlah kopi dan suhu dalam ruang roastin serta variable output yaitu pada lama waktu sangria, seperti pada gambar 2 berikut :

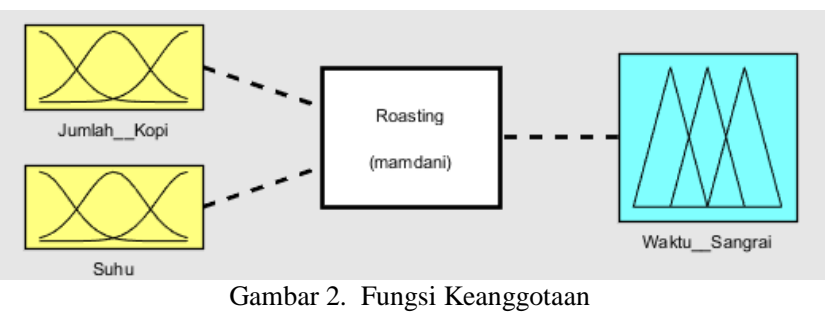

\section{HASIL DAN PEMBAHASAN}

Pada hasil dan pembahasan ini untuk mengamati dan menganalisa dari setiap pengujian pada setiap blok diagram yaitu pengujian sensor suhu dan pengujian terhadap output.

\section{A. Pengujian Sensor Suhu}

Pengujian sensor suhu ini dilakukan untuk mengetahui tingkat akurasi dari sensor suhu yang digunakan, dimana pengujian dilakukan dengan membandingkan antara sensor suhu dengan thermometer thermocouple. Hasil pengamatan seperti pada tabel 1 berikut :

\begin{tabular}{ccc}
\multicolumn{2}{c}{ Tabel 1. Data Perbandingan Sensor Suhu dengan Thermocouple } \\
\hline \multirow{2}{*}{ Pengujian ke- } & \multicolumn{2}{c}{ Suhu $\left({ }^{\circ} \mathbf{C}\right)$} \\
\cline { 2 - 3 } & Thermometer & Sensor Suhu \\
\hline $\mathbf{1}$ & 38,3 & 37 \\
$\mathbf{2}$ & 45,2 & 45 \\
$\mathbf{3}$ & 60,6 & 59 \\
$\mathbf{4}$ & 80,3 & 80,3 \\
$\mathbf{5}$ & 100,8 & 101 \\
$\mathbf{6}$ & 125,5 & 125 \\
$\mathbf{7}$ & 150,7 & 150,5 \\
$\mathbf{8}$ & 202,6 & 201,8 \\
$\mathbf{9}$ & 205,8 & 204,2 \\
$\mathbf{1 0}$ & 210,2 & 120 \\
\hline
\end{tabular}

Berdasarkan table 1 didapatkan hasil pengujian senor dengan suhu yang terbaca oleh thermometer dan sensor suhu berbanding lurus. Pembacaan sensor suhu selalu mendekati hasil pembacaan dari thermometer.

\section{B. Pengujian Fuzzy Logic}

Pengujian fuzzy logic dilakukan untuk menentukan variable fuzzy sehingga dapat ditentukan fungsi keanggotaannya. Dari fungsi keanggotaan didapatkan derajat keanggotaan jumlah kopi seperti pada gambar 3

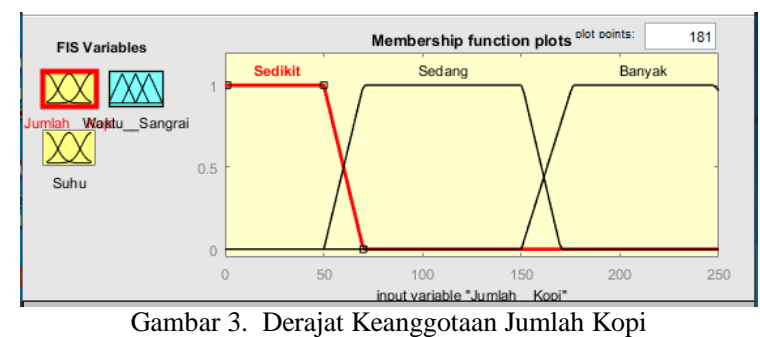

Berdasarkan gambar 3, menggunakan kurva bahu oada derajat keanggotaan sedikit dan pada derajat keanggotaan banyak serta menggunakan kurva trapesium pada derajat keanggotaan sedang. Menggunakan model tersebut karena nilai titik puncak pada setiap variabel memiliki nilai lebih dari satu range nilai. Variabel derajat jumlah kopi seperti pada tabel 2 berikut

Tabel 2. Variabel Derajat Jumlah Kopi

\begin{tabular}{cc}
\hline Derajat Jumlah Kopi & Jumlah Kopi (Gram) \\
\hline Sedikit & $\leq 70$ \\
Sedang & $50-170$ \\
Banyak & $170-250$ \\
\hline
\end{tabular}

Untuk fungsi keanggotaan dapat dirumuskan sebagai berikut :

$$
\begin{gathered}
\mu(\text { sedikit })=\left\{\begin{array}{cc}
70-x & 1, x \leq 50 \\
70-50 & 50<x \leq 70 \\
0, x>70
\end{array}\right. \\
\mu[\text { sedang }]=\left\{\begin{array}{cc}
\frac{x-50}{70-50} & 0, x \leq 50 \text { atau } 170 \\
\frac{170-x}{170-150} & 1, x \leq 150
\end{array}\right. \\
\mu[\text { banyak }]=\left\{\begin{array}{cc}
\frac{x-150}{170-150} & 150<x \leq 170 \\
& 0, x \leq 150
\end{array}\right.
\end{gathered}
$$

Untuk fungsi keanggotaan dari derajat keanggotaan sensor suhu seperti pada gambar 4 berikut 


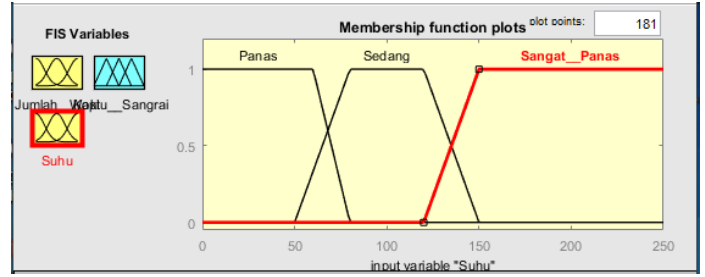

Gambar 4. Derajat Keanggotaan Sensor Suhu

Berdasarkan gambar 4 menggunakan kurva bahu pada derajat keanggotaan panas dan pada derajat keanggotaan sangat panas serta menggunakan kurva trapesium pada derajat keanggotaan sedang. Penggunaan model tersebut karena niai titik puncak setiap variabel memiliki nilai lebih dari satu range. Variabel derajat suhu seperti pada tabel 3 berikut

Tabel 3. Variabel Derajat Suhu

\begin{tabular}{cc}
\hline Derajat Suhu & Suhu $\left({ }^{\circ} \mathrm{C}\right)$ \\
\hline Panas & $\leq 80$ \\
Sedang & $80-150$ \\
Sangat Panas & $150-250$ \\
\hline
\end{tabular}

Untuk fungsi keanggotaan dapat dirumuskan sebagai berikut :

$$
\begin{gathered}
\mu(\text { Panas })=\left\{\begin{array}{lc}
\frac{80-x}{80-50} & 1, x \leq 50 \\
0, x>80
\end{array}\right. \\
\mu[\text { sedang }]= \begin{cases}\frac{x-50}{00-50} & 0, x \leq 80 \text { atau }>150 \\
\frac{150-x}{150-120} & 1, x=150\end{cases} \\
\mu[\text { Sangat panas }]= \begin{cases}\frac{x-120}{150-120} & 1, x \geq 150 \\
& 0, x \leq 120\end{cases}
\end{gathered}
$$

Untuk output pada lama proses sangrai dapat digambarkan derajat keanggotaannya seperti pada gambar 5 berikut

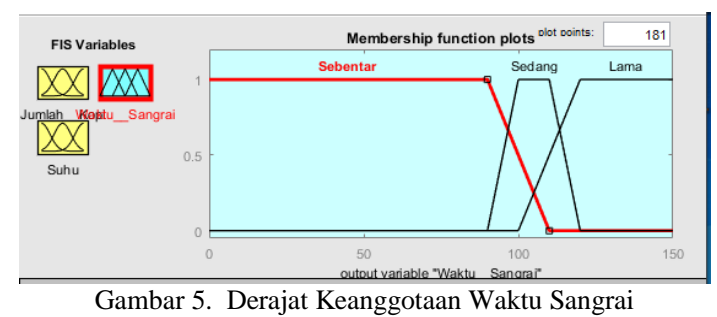

Berdasarkan gambar 5 , merupakan output waktu proses sangrai, dimana sebentar berarti waktu sangrai kurang dari 90 menit, sedang berarti waktu sangrai antara 90 menit sapai 120 menit dan lama yaitu dengan waktu 120 menit sampai 150 menit.

Rule fuzzy disusun berdasarkan derajat keanggotaan pada input dan output, rule fuzzy dapat ditulisakan pada tabel 4

Tabel 4. Rule Fuzzy Output

\begin{tabular}{ccc}
\multicolumn{3}{c}{ Tabel 4. Rule Fuzzy Output } \\
\hline \multicolumn{2}{c}{ Input } & Output \\
\hline Jumlah Kopi & Suhu & Waktu Sangrai \\
\hline Sedikit & Panas & Sedang \\
Sedikit & Sedang & Sedang
\end{tabular}

$\begin{array}{lcc}\text { Sedikit } & \text { Panas Sekali } & \text { Sebentar } \\ \text { Sedang } & \text { Panas } & \text { Sedang } \\ \text { Sedang } & \text { Sedang } & \text { Lama } \\ \text { Sedang } & \text { Panas Sekali } & \text { Sedang } \\ \text { Banyak } & \text { Panas } & \text { Lama } \\ \text { Banyak } & \text { Sedang } & \text { Lama } \\ \text { Banyak } & \text { Panas Sekali } & \text { Sedang }\end{array}$

Berdasarkan tabel 4, output pada lama proses sangrai terdapat tiga pengelompokan waktu sangrai, yaitu sebentar, sedang dan lama. Fungsi keanggotaan output dapat dirumuskan sebagai berikut :

$$
\begin{gathered}
\mu(\text { Sebentar })=\left\{\begin{array}{cc}
110-x & 1, x \leq 90 \\
110-90 & 90<x \leq 110 \\
0, x>110
\end{array}\right. \\
\mu[\text { sedang }]=\left\{\begin{array}{cc}
\frac{x-90}{100-90} & 0, x \leq 90 \text { atau }>120 \\
\frac{120-x}{120-110} & 110<x \leq 100
\end{array}\right. \\
\mu[\text { Lama }]=\left\{\begin{array}{cc}
\frac{x-100}{120-100} & 100<x \leq 110 \\
120 \leq 120 & 0, x \leq 100
\end{array}\right.
\end{gathered}
$$

\section{Hasil Pengujian Waktu Sangrai}

Pengujian waktu sangrai sangat bergantung pada jumlah kopi dan suhu ruang roasting, dimana kedua variable tersebut sangat mempengaruhi waktu sangrai. Proses memasukkan kopi ke ruang roasting dilakukan jika suhu sudah mencapai setting suhu yang diinginkan.

\begin{tabular}{cccc}
\multicolumn{4}{c}{ Table 5. Pengujian Waktu Sangrai } \\
\hline No & Jumlah Kopi (Gram) & Suhu $\left({ }^{\circ} \mathrm{C}\right)$ & $\begin{array}{c}\text { Waktu Sangrai } \\
(\text { Menit })\end{array}$ \\
\hline 1 & 70 & 80 & 60 \\
2 & 70 & 90 & 45 \\
3 & 100 & 110 & 50 \\
4 & 150 & 145 & 115 \\
5 & 165 & 150 & 100 \\
6 & 175 & 160 & 110 \\
7 & 190 & 140 & 113 \\
8 & 200 & 100 & 105 \\
9 & 210 & 170 & 110 \\
10 & 250 & 180 & 100 \\
\hline
\end{tabular}

Berdasarkan tabel 5, jumlah kopi yang disangrai sangat dipengaruhi oleh suhu pada setiap proses roasting, sehingga memili keterkaitan dengan waktu proses sangrai.

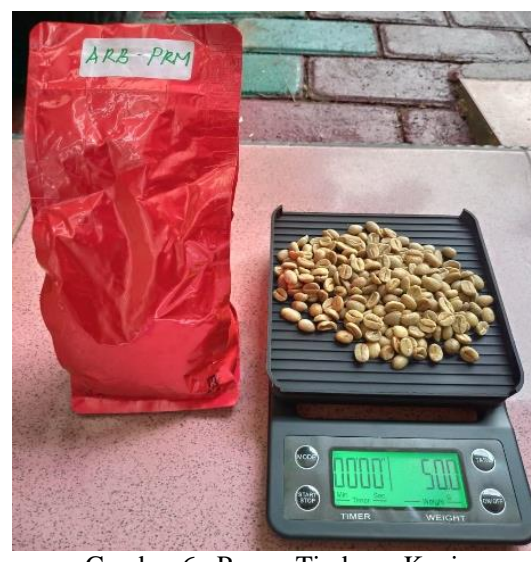

Gambar 6. Proses Timbang Kopi

Berdasarkan gambar 6, proses untuk mendapatkan jumlah kopi dalam bentuk gram digunakan timbangan digital untuk mempermudah pembacaan berapa gram kopi yang akan disangrai. 


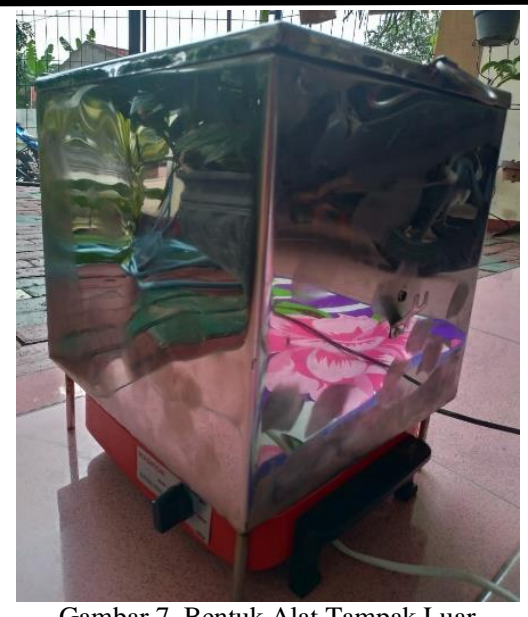

Gambar 7. Bentuk Alat Tampak Luar

Berdasarkan gambar 7, merupakan bentuk alat sangrai kopi tampak luar dengan berbahan stanlais stell. Pada bagian bawah terdapat elemen panas, dimana elemen panas tersebut memanfaatkan kompor listrik.

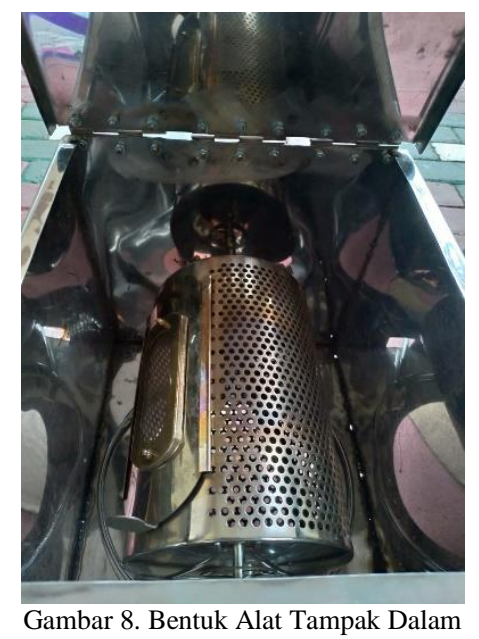

Berdasarkan gambar. 8, bentuk alat tampak dalam ini merupakan bentuk tabung dengan terdapat lubang pada setiap sisi nya. Tabung ini nanti akan berputar secara konstan yang berfungsi untuk mengaduk kopi agar mendapatkan pemerataan panas waktu proses sangrai.

\section{KESIMPULAN}

Proses roasting yang masih manual adalah pada penentuan suhu dan lama proses Roasting dalam satu kali produksi. Solusi untuk permasalah tersebut adalah dengan merancang system kendali dan otomasi pada mesin roasting kopi. Dengan mengontrol dan mengendalikan suhu dengan menggunakan metode fuzzy logic pada proses Roasting diharapkan dapat menciptakan rasa dan aroma yang berbeda serta proses produksi lebih cepat. Dimana jumlah kopi dengan suhu yang telah ditentukan akan memberikan pengaruh pada waktu proses sangrai, jumlah kopi 100 gram dengan suhu $110^{\circ} \mathrm{C}$ membutuhkan waktu sangrai +50 menit.

\section{REFERENSI}

J. A. Siahaan, "Analisis daya saing komoditas kopi arabika indonesia di pasar internasional," Skripsi. Progr. Stud. Ekon. Pertan. dan Sumberdaya. Inst. Pertan. Bogor. Bogor, 2008.

[2] R. Kustiari, "Perkembangan pasar kopi dunia dan implikasinya bagi Indonesia," 2016.

[3] L. Hidayah, "Analisis Rantai Pasok (Supply Chain) Kopi Robusta Pada Kelompok Tani 'Tani Maju' Desa Baturetno Kecamatan Dampit Kabupaten Malang." Universitas Brawijaya, 2016.

[4] A. Permana and I. Setiono, "Sistem Pengendalian Suhu dan Pemantauan Kelembaban Biji Kopi pada Mesin Penyangrai Berbasis Arduino 2560," Gema Teknol., vol. 19, no. 2, pp. 1923.

[5] F. Tampubolon, Y. Pratama, and I. G. E. Dirgayussa, "Perancangan, Implementasi Monitoring dan Kontrol Alat Pemanggang Kopi," ELKHA J. Tek. Elektro, vol. 12, no. 2, pp. $69-75$.

[6] I. Elektronik, "Manual MAX 6675 K-Type Thermocouple Temperature Sensor," Semarang, 2014.

[7] R. Arifuddin, "Pengembangan Sistem Akuisisi Data Terdistribusi Nirkabel Untuk Pengukuran Dan Mapping Suhu Bawah Permukaan.” Universitas Brawijaya, 2015.

[8] R. Arifuddin and Y. Sinatra, "Identifikasi Sensor Suhu pada Setup Awal Untuk Pengukuran Suhu Bawah Permukaan," JEECAE (Journal Electr. Electron. Control. Automot. Eng., vol. 3, no. 2, pp. 209-212, 2018.

[9] S. B. Utomo, M. Agung, and S. Sumardi, "Perancangan Sistem Pengaturan Suhu pada Mesin Sangrai Kopi Berbasis Logika Fuzzy," Rekayasa Mesin, vol. 6, no. 2, pp. 119-126, 2015. 